\title{
O SISTEMA INTERNACIONAL NO ANTROPOCENO
}

\section{Eduardo Viola}

Eduardo Viola, Universidade de Brasília (UnB), Brasília - DF. E-mail: eduviola@gmail.com

\section{Larissa Basso}

Larissa Basso, Universidade de Brasília (UnB), Brasília - DF. E-mail: larissabasso@gmail.com

DOI: $10.17666 / 319201 / 2016$

\section{Introdução}

Uma grande mudança teve início com a Revolução Industrial, ganhou fôlego ao longo da aceleração demográfica, econômica e tecnológica ocorrida entre 1940 e 2000 e consolidou-se nas últimas décadas, fins do século XX e início do século XXI: a transição do Holoceno para o Antropoceno. O Holoceno foi o período de estabilidade ambiental experimentado desde a última glaciação terminada há aproximadamente 11 mil anos - até o terceiro quarto do século XX, durante o qual a humanidade desenvolveu-se. O Antropoceno é a nova e atual época geológica em que essa estabilidade está sendo progressivamente perdida por conta da atuação da humanidade, que se tornou o principal vetor de mudanças no sistema planetário. As consequências

Artigo recebido em 11/02/2015

Aprovado em 29/04/2016 dessa transformação têm magnitude nunca antes experimentada pela humanidade; foram compreendidas e internalizadas rapidamente pelas ciências naturais, mas ainda escapam, em grande medida, às ciências sociais e humanas.

O fim da estabilidade ambiental significa que conceitos de ameaça e segurança precisam ser atualizados. A maior ameaça à segurança sistêmica tende a ser, cada vez mais, a ultrapassagem dos limites planetários, não as guerras no centro do sistema como foi até o século XX, dada a improbabilidade de uma guerra sistêmica neste início do século XXI. Ultrapassar os limites planetários significa colocar em risco a sobrevivência humana como espécie. E a ultrapassagem resulta de modelos de desenvolvimento adotados, especialmente padróes de produção e consumo e uso de combustíveis fósseis como principal fonte de energia. Por isso, também o conceito de interesse nacional precisa ser atualizado: dado que para mitigar mudanças tão significativas 
no sistema planetário é essencial alcançar cooperação que vá além do mínimo denominador comum, é necessário aprofundar a governança global, o que implica cessão de soberania em favor de acordos intergovernamentais mais robustos.

O objetivo deste artigo é demonstrar como o Antropoceno ainda não foi internalizado em grande parte da produção das Relaçóes Internacionais e como a internalização torna necessário redefinir conceitos tradicionais da disciplina. Para tanto, o trabalho será dividido em três partes. Na primeira será tratado do tema do Antropoceno, seu significado e o desafio que representa para as relações internacionais. $\mathrm{Na}$ segunda será traçada a atual conjuntura internacional, com evidências do retrocesso na cooperação internacional e o aumento da conflituosidade e da incapacidade de regimes internacionais em tratar de problemas comuns globais, em especial a instabilidade ambiental. Na terceira será demonstrado como a atualização dos conceitos de ameaça, segurança e interesse nacional, além do aprofundamento da governança global, podem tornar a geopolítica muito mais capaz para lidar de forma satisfatória com problemas comuns globais, característicos do século XXI.

\section{O Antropoceno e as relaçóes internacionais}

\section{O conceito de Antropoceno e os limites planetários}

Há aproximadamente 11 mil anos terminou a última glaciação e o planeta entrou em uma era geológica de clima mais ameno e estável, chamada de Holoceno. Esse clima ameno e estável proporcionou à humanidade condiçôes de desenvolvimento não presentes em épocas anteriores para outras espécies; por isso, ao longo do Holoceno, ela passou de alguns grupos de caçadores-coletores para uma população de 6 bilhôes de pessoas, agrupada em complexas organizaçóes sociais com nacionalidades, culturas e modos de vida diversos. O desenvolvimento da humanidade foi paulatino, mas trouxe impactos cumulativos. Em fins do século XX e início do século XXI, a transformação da sociedade industrial para a sociedade de informação/ conhecimento, com aumento exponencial da população global e do consumo per capita de recursos naturais, fez com que a humanidade passasse a ser a principal força de transformação no planeta. Essa é a principal característica da atual época geológica, o Antropoceno.

O Antropoceno foi definido pela primeira vez pelos cientistas Crutzen e Stoemer (2000). Antropoceno é uma nova época geológica e humana, caracterizada pelo protagonismo da humanidade como força transformadora do planeta (Rockstrom et al., 2009; Biermann et al., 2012; Steffen et al., 2015) De acordo com os cientistas, a intensidade dos impactos da humanidade sobre o planeta aumentou de forma exponencial após a Revoluçáo Industrial, portanto ela seria o marco de início da nova época geológica. No entanto, apesar de a Revolução Industrial ter sido o estopim do processo que desencadeou o Antropoceno, à época os impactos da humanidade sobre o planeta ainda náo tinham cumulado ou alcançado a escala que tornou o homo sapiens a principal força transformadora terrestre. Por isso, entende-se que o Antropoceno se consubstancia no início do século XXI, quando os requisitos de escala e cumulatividade foram alcançados (Viola, Franchini e Ribeiro, 2013).

Um dos fatores motrizes da Revolução Industrial foi o uso massivo dos combustíveis fósseis. Com o uso desses, a restrição energética que limitava as atividades humanas ${ }^{1}$ foi superada (Steffen $e t$ al., 2011, p. 848). O uso do carvão e do petróleo permitiu que a humanidade desenvolvesse a metalurgia e as máquinas, a indústria química e os fertilizantes agrícolas, a eletricidade e o motor de combustão interna; que revolucionasse as comunicaçôes e os sistemas produtivos para a produção em massa. Tantas transformaçóes, impactantes em si mesmas, não teriam alcançado escala planetária sem seu emprego disseminado por um número cada vez maior de seres humanos. De fato, entre 1945 e 2000, a população mundial passou de 3 bilhóes para 6 bilhôes de pessoas; o consumo de petróleo aumentou em quase quatro vezes, a atividade econômica aumentou em quinze vezes, e a urbanização e os padróes de consumo de massa disseminaram-se (Steffen et al., 2011). 
O início do Antropoceno coincide com a ultrapassagem dos limites planetários. Os limites planetários - mudança do clima, integridade da biosfera, fluxos biogeoquímicos do nitrogênio e do fósforo, diminuição da camada de ozônio, acidificação dos oceanos, uso da água doce, uso dos solos, poluição agregada global por aerossóis e contaminação química (Rockstrom et al., 2009; Steffen et al., 2015) - são limites de resiliência do planeta: se ultrapassados, a estabilidade ambiental é perdida. Dois limites encontram-se ultrapassados: os fluxos biogeoquímicos do nitrogênio e do fósforo, em razáo do uso massivo de fertilizantes desde os anos de 1950, e a integridade da biosfera, como consequência da expansão da população humana, que impactou ecossistemas naturais e outras espécies a ponto de extingui-las - é a sexta grande extinção em 4 bilhóes de anos de história da vida, a primeira produzida pela humanidade. A estabilidade do clima foi quebrada, em razão da acumulação de gases de efeito estufa (GEE) na atmosfera. Como resultado, está atualmente em curso a mudança do clima incremental, que pode, se não mitigada, evoluir para perigosa e posteriormente catastrófica.

A mudança do clima incremental resulta em eventos climáticos extremos cada vez mais frequentes: chuvas mais intensas e concentradas; secas mais extremas; extremos prolongados de calor e frio; choques mais intensos entre circulação atmosférica oceânica e terrestre em muitas regióes litorâneas; sequências de furacóes e tufōes; retração extensa e prolongada do gelo nos verôes do oceano Ártico; início de liberação de metano acumulado na tundra siberiana e canadense. Esses eventos, no curto prazo, ameaçam segmentos da população mais vulneráveis, particularmente os mais pobres em diversas partes do planeta. No longo prazo, podem tornar mais custosos e menos previsíveis os sistemas energéticos, de telecomunicaçóes e de transporte.

Caso a mudança climática em curso não seja mitigada, poderá evoluir para a mudança climática perigosa. Esta seria caracterizada por: potencial de destruição de produção agrícola; escassez de água; extremos climáticos mais intensos; aumento da turbulência do mar e ondas anormais que invadem temporariamente as regióes costeiras - e a maioria da população do mundo vive em áreas costeiras. Se ainda esta não for mitigada, chegar-se-ia à mudança climática catastrófica, os chamados tipping points: fim da corrente do Golfo, que é fundamental para o clima ameno da Europa; liberação generalizada do metano da tundra canadense e siberiana, em razão do degelo dessas regióes; incêndios generalizados na Amazônia e outras florestas tropicais remanescentes (Congo, Indonésia); derretimento do gelo na Groelândia; colapso de parte do gelo da Antártida; mudança no ciclo monçôes na Ásia; aumento do nível do mar entre 50 e 100 metros, inundando grande parte das cidades. A probabilidade de mudança climática catastrófica é hoje muito baixa, mas ela aumentará progressivamente caso a humanidade não consiga conter a concentração de carbono na atmosfera, e uma mudança climática nesse nível implicaria o fim da civilização, senão a extinção da espécie humana.

Retomar um espaço seguro para a existência humana na Terra requer mitigar a ultrapassagem dos limites planetários. Todavia, há descompasso entre as medidas necessárias para essa mitigação e o que a atual geopolítica tem oferecido como resposta a essas questóes.

\section{Os desafios do Antropoceno e a realidade da geopolitica}

A mitigação da mudança climática é um bem comum global. Bens comuns são caracterizados pela não exclusividade - não é possível excluir de seu uso aqueles que náo contribuem para sua provisão. Por isso, partes individualmente consideradas não têm interesse em sua provisão: é necessário algum arranjo cooperativo para que esses bens sejam providos. A estabilidade do clima, no entanto, têm características que dificultam a formação de arranjos cooperativos eficientes para sua provisão: (i) é intrinsicamente global, centrada em alterações na atmosfera; (ii) opera em uma escala de tempo de longo prazo estranha à experiência quotidiana humana, pois décadas podem ocorrer entre a adoção de medidas de mitigação e a observância de seus efeitos; (iii) envolve profundas questóes de equidade, intra e intergerações; (iv) náo apresenta linearidade causa-efeito; (v) entre suas causas está um leque amplo de atividades quotidianas huma- 
nas, o que torna impossível que sua solução seja alcançada por uma medida única (Steffen, 2011, pp. 22-26; Underdal, 2010, p. 386). A mudança do clima é um problema complexo e de tratamento bastante difícil; sua mitigação requer a implementação de medidas que tocam questóes centrais da realidade contemporânea, como fontes de energia, estilos de vida, instituiçóes e governança, formas de organização econômica e valores (Jamieson, 2011, pp. 38-42; Steffen, 2011, p. 21). Instituiçôes e sistemas jurídicos atuais, centrados na lógica causa-efeito de curto prazo e na provisão de bens privados, não estão preparados para lidar com a mudança do clima (Steffen, 2011; Underdal, 2010) - e isso é verdade tanto na esfera interna como na internacional.

Para mitigar as mudanças climáticas, é preciso reduzir a concentração de GEE, especialmente o carbono, na atmosfera, ou seja, descarbonizar. São doze os vetores principais para a descarbonização global: (i) acelerar extraordinariamente o ritmo da eficiência energética; (ii) descarbonizar a matriz energética mundial (diminuindo drasticamente o uso do carvão, estabilizando o uso do petróleo e aumentando significativamente o uso das energias renováveis e, em menor medida, do gás natural e da energia nuclear); (iii) aumentar radicalmente a proporção do transporte coletivo na mobilidade humana e, quando houver necessidade de transporte individual, usar carros elétricos, de hidrogênio, de biocombustíveis ou híbridos; (iv) parar o desmatamento e reflorestar/florestar massivamente; (v) utilizar técnicas agropecuárias virtuosas como plantio direto, agricultura de baixo carbono e mínimo uso de fertilizantes nitrogenados; (vi) reduzir o consumo de carne (particularmente de gado, cujo ciclo produtivo produz uma quantidade enorme de metano e consome muita água) nos países de renda alta e média; (vii) usar eficientemente a água; (viii) baixar rapidamente a taxa de fecundidade na África, Oriente Médio e sul da Ásia; (ix) acelerar o desenvolvimento de tecnologias de captura e sequestro de carbono fóssil; (x) diminuir as reunióes presenciais e substituí-las por reunióes virtuais; (xi) diminuir a velocidade de crescimento do tráfego aéreo (incluída uma revolução tecnológica de eficiência energética de novos materiais mais leves), cujas emissóes são as que mais crescem entre todos os setores da economia mundial; (xii) avançar rapidamente na densidade da cooperação internacional sobre novas tecnologias de baixo carbono, incluídas as relacionadas com a geoengenharia climática (manejo da radiação solar e do comportamento das nuvens e outras) (Viola, Franchini e Ribeiro, 2013, pp. 143-144; The Royal Society 2012; Parsons e Ernst 2014). Essas mudanças exigem novas tecnologias e designs, mas, principalmente, mudanças políticas e culturais, que são altamente influenciadas por complexos processos sociais e psicológicos (Veiga, 2013).

No fundamental, o desafio não é tecnológico. Houve desenvolvimento significativo de tecnologias para aumentar a eficiência energética e o uso de fontes energéticas de baixo carbono: eletrodomésticos com menos gasto de energia/intensivos; técnicas para aproveitamento da luz solar em edifícios; aquecimento de água por energia solar; eletricidade gerada por energia eólica, solar fotovoltaica, gases de aterros sanitários, nuclear, energia geotérmica e marés - incluindo expansão do uso de baterias e de smart grid; veículos movidos a gás natural, biomassa e íons de lítio. Outra quantidade de tecnologias está em estágio pré-comercial, e muitas outras encontram-se em estágios de demonstraçáo ou pesquisa e desenvolvimento (Diesendorf, 2011, p. 565).

No entanto, as respostas políticas para a mudança do clima têm sido insatisfatórias. Até agora, emissóes de GEE continuam crescendo ao ritmo de aproximadamente $2 \%$ ao ano, mesmo que de modo bastante heterogêneo entre os diversos países. Neste nível de crescimento, o limite do orçamento global de carbono - o que os climatologistas avaliam como as emissóes que nos restam para evitar a mudança climática perigosa - seria atingido em torno de 2040. O insucesso do regime do clima em mitigar o problema é resultado da discrepância entre a natureza da questão climática e as características do sistema internacional contemporâneo: (i) o aumento da conflituosidade e (ii) o modelo de tomada de decisóes, que resulta no mínimo denominador comum e trava o avanço da negociação de temas comuns globais. 


\section{Atual conjuntura internacional: a humanidade ameaçada por seu passado e por seu futuro}

\section{Retorno ao passado? Aumento da conflituosidade no sistema internacional}

Ao contrário do que imaginavam os mais otimistas do pós-guerra, o mundo não caminhou para a paz perpétua. A segunda metade do século XX viu crescer de forma considerável a cooperação multilateral entre os países: floresceram regimes internacionais nos mais diversos temas - comércio, finanças, investimentos, saúde pública, comunicações, meio ambiente, direitos humanos -; questôes que ameaçavam o futuro da humanidade, como a proliferação de armas nucleares, tiveram encaminhamento relativamente satisfatório. De fato, desde 1990, a guerra simétrica entre as grandes potências é muito improvável: houve importante aumento da interdependência sistêmica, que encaminha a cooperação internacional em todos os níveis. No entanto, forças conflitivas voltaram a ganhar ânimo nos últimos quinze anos, em diversas regióes do mundo.

Neste início do século XXI, as principais tendências, com diverso potencial de conflituosidade, que interferem na estabilidade do sistema internacional, são oito. Primeira, mudanças na balança de poder entre Estados, com o deslocamento parcial e gradual do poder do mundo ocidental para a Ásia/Pacífico. Segunda, o crescimento do poder relativo de atores não estatais (empresas, ONGs, governos subnacionais, organizaçóes religiosas, redes societais, crime organizado, grupos terroristas) no interior dos Estados nacionais, e consequente crescimento do poder relativo de atores não estatais internacionais em relação aos Estados e às organizaçôes intergovernamentais. Terceira, a diminuição da influência dos Estados Unidos como garantidor de última instância da estabilidade global. Quarta, o aumento quase generalizado da desigualdade na distribuição das riquezas no interior das naçóes e entre algumas nações (as de renda per capita alta e média em relação às de baixa renda). Quinta, a natureza do poder na sociedade da informação que facilita a contestação e eventual erosão dos poderes estabelecidos, mas muito mais difícil a construção de novos poderes (Naim, 2013). Sexta, o crescimento extraordinário das capacidades para guerra cibernética e grande dificuldade para limitá-la e regulá-la. Sétima, a dificuldade para alcançar a cooperação entre os principais Estados em um leque de problemas comuns globais. Oitava, o fortalecimento em vastos setores da população mundial de identidades de tipo adscritivas (religiosa e étnica), incluindo o fortalecimento de versôes fundamentalistas das grandes religióes monoteístas - cristianismo, islamismo e judaísmo -, com o correspondente acirramento de conflitos religiosos (Hoge, 2010).

Diversos são os epicentros geopolíticos dessas forças centrífugas. No leste e sul da Ásia e na crise entre Rússia e Ucrânia, há o renascimento de nacionalismos agressivos. No grande Médio Oriente, há tendências de desintegração dos Estados nacionais combinadas com guerras étnico/religiosas e desenvolvimento de redes terroristas de escopo global. Em âmbito global, há contínuo crescimento do poder do ilícito transnacional e das redes terroristas, e grande dificuldade em combatê-las. Paira, no mundo ocidental, um sentimento de impotência para lidar com áreas altamente conflitivas, o que leva à não intervenção (ou isolacionismo relativo). Sem a interferência externa, esses conflitos desenrolam-se por longos períodos até alcançarem, em alguns casos (Somália, Congo, Síria, Iraque, Líbia, Mali, Chade, Iêmen, Sudão, Zimbábue), níveis sangrentos extremos, o que não acontecia em grande escala desde 1945 (exceto em Ruanda, em 1994). Desse modo, não é irreal pensar que conflitos regionais possam se desenrolar por anos e até décadas - o combate ao Estado Islâmico configura-se para alguns internacionalistas como "uma nova Guerra dos Trinta Anos" (por analogia com as guerras religiosas europeias de início do século XVII), por exemplo.

Este cenário representa um retrocesso significativo em relação ao mundo que se almejou construir no pós-guerra. $\mathrm{O}$ direito internacional, avanço importante da cooperação humana, é baseado na igualdade normativa e tem efeitos limitados sobre uma realidade dominada pelas disparidades de riqueza e poder. Quando se enfrentam problemas complexos de provisão de bens comuns globais, 
como a mudança do clima, a discrepância entre realidade desigual e a igualdade normativa torna-se ostensiva, e explica, em grande medida, a incapacidade do regime internacional para obter soluçóes eficientes para a questão.

\section{Incapacidade dos regimes em mitigar a ultrapassagem dos limites planetários}

A geopolítica contemporânea, assim como a maioria das ciências sociais, é construída sobre pressupostos de um meio ambiente estável para as atividades humanas - o meio ambiente como pano de fundo para o drama humano (Dalby, 2013, p. 189). O Antropoceno representa o fim dessa estabilidade, o que, porém, ainda foi minimamente incorporado pelas relaçóes internacionais: as análises continuam caracterizando como grandes ameaças à estabilidade da civilização apenas os conflitos entre as potências. A ameaça da instabilidade ambiental é, porém, de escala crescentemente significativa, mesmo que ainda não tenha atingido a gravidade imediata dos conflitos humanos. Envolve fatores fundamentais para a sobrevivência da espécie, como eventos climáticos extremos, escassez de água doce, acidificação dos oceanos, grandes perdas de solos agrícolas, florestas e espécies animais e vegetais, de impacto tão relevante quanto o da Primeira e Segunda Guerras Mundiais. Em termos de instabilidade no sistema internacional e possibilidade de perdas materiais e humanas, o risco da mudança climática perigosa não equivale ao de uma guerra simétrica entre potências que ocupam o centro do sistema. No entanto, tem impacto muito mais alto do que guerras assimétricas inter e intraestatais, que ocorrem desde 1945.

O cálculo do risco desenvolvido na época do Holoceno está baseado em dois pressupostos: situações de alto risco são aquelas que têm alto impacto mas probabilidade pequena de acontecer, e situaçóes de baixo risco são as que têm baixo impacto mas probabilidade alta de ocorrência (Dalby, 2013, pp. 188-189). Esse raciocínio está enraizado na psiquê humana. Em política internacional, conflitos localizados são considerados de baixo risco: são comuns, mas representam pouco risco para a estabilidade do sistema internacional; situações de alto risco, por sua vez, são raras, mas devastadoras se concretizadas - a guerra nuclear ou as ameaças terroristas de grande escala (atentados com uso de armas radiológicas ou bacteriológicas que causem a morte de milhôes de pessoas). Os limites planetários não se encaixam em nenhuma das duas categorias: a mudança do clima, por exemplo, tem alto impacto e alta probabilidade de acontecer, dados os fatos verificados pela ciência (Dalby, 2013, pp. 188-189).

A mudança do clima tem algumas semelhanças com ameaças nucleares e terroristas: (i) há incerteza em relação à sensibilidade, gama, escala, velocidade e natureza descontínua das ameaças; (ii) há incerteza em relação à efetividade e confiabilidade de estratégias de resposta; (iii) há certeza de que as consequências das ameaças para a segurança internacional requereriam intervençóes militares se forem mal administradas, mas que o desmantelamento das ameaças requer, acima de tudo, ação civil que toque as causas do problema (Dalby, 2013, p. 189). Guarda, porém, uma diferença extraordinária: o sistema climático, ao contrário das ameaças nucleares e terroristas, escapa à discricionariedade humana, pois vai inevitavelmente seguir as leis da física - o aumento da concentração de GEE leva ao aumento da temperatura média do planeta e à quebra dos padrooes de clima estável. Na mudança do clima, a ação humana não é capaz de deter a relação causa-consequência; sua atuação interfere apenas para determinar seus níveis (Dalby, 2013, p. 189).

A resposta no sistema internacional para a mudança do clima foi o desenvolvimento do regime internacional sobre mudanças climáticas. Sua evolução é bastante conhecida. Antes de 1990, a preocupação era com a definição do problema (Gupta, 2010). Em 1992, foi assinada a Convenção Quadro das Naçóes Unidas sobre Mudanças Climáticas (CQNUMC), que estabelece os parâmetros para negociação do tema das mudanças climáticas e inaugura a busca de soluçóes para o problema, mas não elenca obrigações específicas de implementação. Ficou decidido que obrigações específicas seriam discutidas em reuniōes periódicas, chamadas Conferências das Partes (COPs), de modo a definir as estratégias de implementação das obrigaçóes assumidas. As COPs ocorrem desde 1995, e os con- 
textos de três delas são especialmente importantes para a trajetória do regime: a COP 03 (Kyoto), a COP 15 (Copenhagen) e a COP 21 (Paris).

A COP 03 ocorreu em 1997 e o Protocolo de Quioto foi assinado pelos países membros da CQNUMC na ocasião. $\mathrm{Na}$ fase de negociação do Protocolo, economias industrializadas assumiram a liderança nos compromissos de redução de emissóes de GEE (Gupta, 2010; Viola, 2002). O protocolo estabelece que essas economias, agrupadas no Anexo I da CQNUMC, deveriam impor limites compulsórios para suas emissóes, reduzindo-as em pelo menos 5\% entre 2008 e 2012 em relação aos patamares de 1990. No contexto da negociação, as economias emergentes foram pressionadas mas rejeitaram compromissos de redução de suas curvas de emissões (em relação a cenários business as usual) para o mesmo período (Viola, 2002). Elas articulavam-se principalmente por meio do G-77+China, lideradas pelo Brasil, Índia e China, utilizando o princípio das responsabilidades comuns, porém diferenciadas, e a responsabilidade histórica das economias desenvolvidas para justificar seu posicionamento. Entre 1997 e 2001, o regime do clima caminha para a consolidação (Gupta, 2010), mas tem um revés, pois os Estados Unidos deixam a liderança: decidem não ratificar o Protocolo de Quioto alegando que sua competição em mercados internacionais com economias emergentes não obrigadas a reduzir emissóes era desleal. O Protocolo entrou em vigor em 2005 obrigando a redução de emissóes de países que, juntos, correspondiam a apenas $29,91 \%$ do total global de emissóes no mesmo ano (IEA, 2007). ${ }^{2}$

O contexto da COP 15 era mais complexo. Havia grande expectativa de assinatura de um acordo legalmente vinculante que substituiria o Protocolo de Quioto após 2012. A Uniâo Europeia vinha tendo uma atuação destacada de liderança, propondo compromissos fortes e diferenciados para todos os países, mas China, Estados Unidos e Índia mantinham posições modestas. Os resultados da Conferência foram mínimos: os países do Anexo I da Convenção foram instados a propor metas quantificadas, mas voluntárias, de redução de emissóes que alcançassem toda a economia, enquanto os países não Anexo I deveriam apresentar açóes de mitigação nacionalmente apropriadas (NAMAs, em inglês), nos dois casos para cumprimento até 2020. O texto foi construído pelos Estados Unidos e a coalizão BASIC - Brasil, África do Sul, Índia e China -, cujos países seguiam resistentes a assumir obrigações de redução de emissões, mas não queriam ser taxados de culpados pelo fracasso da Conferência (Dubash, 2010; Hallding et al., 2011). O Acordo de Copenhague não é legalmente vinculante nem foi adotado oficialmente, uma vez que Bolívia, Sudão e Venezuela se opuseram a seus termos, impedindo o consenso. Ao contrário de reduzir emissóes de GEE, os compromissos apresentados pelos países representam, em todos os casos, exceto o da União Europeia, aumentos em relação aos patamares de emissōes em $1990 .^{3}$

As negociaçóes do acordo que substituiria o Protocolo de Quioto a partir de 2012 seguiram em meio a grandes discordâncias. Em 2011, foi decidido que um instrumento legalmente vinculante deveria ser acordado até 2015. Em 2012, os membros da UNFCCC assinaram a Emenda de Doha, estabelecendo um segundo período de vigência para o Protocolo de Quioto, de 2013 até 2019. Canadá, Japão e Rússia não assinaram a Emenda. A Emenda ainda não entrou em vigor; ${ }^{4}$ quando entrar, estará vinculando a redução de emissóes de países que representam uma parcela pequena no total global: $13,62 \%$ em 2012; 12,83\% em 2013 (IEA, 2014; 2015). ${ }^{5}$

Em preparação para a COP 21, a polêmica em torno da obrigatoriedade dos compromissos seguia. Apesar do aumento de suas emissóes no total global, as economias emergentes se mantinham resistentes a aceitar metas de redução compulsórias para suas emissóes, alegando a responsabilidade histórica dos países desenvolvidos. Os Estados Unidos continuavam reiterando a necessidade de obrigar os emergentes a reduzir emissôes como condição para aceitar as metas compulsórias para as suas emissóes. Países vinculados pela Emenda de Doha, além de outras representações, ${ }^{6}$ pressionavam pelo maior envolvimento dos demais. Em 2013, foi aprovado que os membros da CQNUMC deveriam apresentar, até 1o de outubro de 2015, Contribuiçóes Nacionalmente Determinadas (Intended Nationally Determined Contributions - INDCs). As INDCs deveriam conter informaçóes detalhadas sobre os compromissos 
de cada membro após 2020, e a maioria dos membros da Convenção as apresentou. O Acordo de Paris, assinado em 2015, é legalmente vinculante (mas aguarda a ratificação de seus membros para entrar em vigor); as INDCs, sua parte fundamental, no entanto, não são: são compromissos voluntários que devem ser revistos periodicamente, com a intenção de serem adaptados conforme sua implementação ocorra. Caso o conjunto das INDCs apresentadas $^{7}$ for totalmente implementado, a temperatura média do planeta subirá 2,7o C até 2100 (Climate Action Tracker, 2015).

$\mathrm{O}$ insucesso do regime em obter a mitigação da mudança do clima decorre das características do atual sistema político-jurídico, desenvolvido para lidar com curto prazo entre ação política e seu efeito, questóes de causa e consequência diretas e relacionadas com atividades determinadas. A mudança do clima é cercada de incerteza e complexidade, e opera no longo prazo. Uma solução mais efetiva para o problema passa pela revisão dos conceitos de ameaça e segurança, com o reconhecimento do Antropoceno, de sua escala e de suas características; pela revisão do conceito de interesse nacional, para além das bases vestfalianas; e pelo aprofundamento da governança global.

\section{Geopolítica para o século XXI}

\section{Ameaças à segurança no Antropoceno}

Reconhecer a realidade do Antropoceno e incorporá-la às bases da geopolítica significa entender que: (i) a mudança do Holoceno para o Antropoceno representa uma transformação profunda e incerta do sistema terrestre, nunca antes experimentada pela espécie humana em sua existência; (ii) essa transformação não é um problema marginal e, sim, resulta das bases do sistema produtivo (Dalby, 2014). Por isso, a noção de ameaças à segurança requer revisão.

Em primeiro lugar, incerteza e complexidade dos problemas ambientais precisam ser incorporadas à matriz cognitiva dos internacionalistas. Se antes o meio ambiente era considerado estável, ante sua grandeza e a incapacidade dos seres humanos de alterá-lo em escala planetária, atualmente a realidade é oposta: a atuação da humanidade modifica-o de maneira profunda e sistêmica. As consequências dessas modificaçóes têm dinâmica incerta e complexa (não linear).

Vejam-se incerteza e complexidade no caso da mudança do clima. A incerteza está relacionada com o longo período de tempo que há entre o acúmulo de GEE na atmosfera e a observância das consequências desse acúmulo, e também entre a adoção de políticas para reduzir os gases estufa e os efeitos dessas políticas (Underdal, 2010, p. 386). A complexidade está relacionada com o fim da linearidade: uma mudança mínima na concentração de gases estufa pode gerar efeitos catastróficos. Políticas que lidam de maneira eficiente com sistemas complexos não dão soluçôes fáceis e rápidas para os problemas: combinam persistência e flexibilidade para lidar com efeitos inesperados e/ou mudanças que surjam ao longo de sua implementação (Underdal, 2010, pp. 388-389). Quando incerteza e complexidade não são reconhecidas em relação à mudança do clima, as potenciais respostas ao problema estarão muito aquém do que é necessário para efetivamente enfrentá-la - o que vem acontecendo no regime do clima.

Em segundo lugar, é preciso levar a sério o peso que o atual modelo de desenvolvimento, adotado pela quase totalidade dos países, tem sobre o futuro. Mudança climática perigosa ou catastrófica não será consequência do choque de um asteroide ou do encapsulamento da Terra por um buraco negro; resultará do consumo inconsequente, do uso indiscriminado de combustíveis fósseis, do desflorestamento, de altíssimas taxas de fecundidade em várias regióes; do uso massivo de fertilizantes e aditivos químicos, entre outros (The Royal Society, 2012). De fato, vive-se, atualmente, uma janela de oportunidade: decisões que forem tomadas nas próximas duas décadas darão origem a consequências que serão experimentadas nos próximos séculos. Assegurar a estabilidade do planeta requer refletir honesta e abertamente sobre sistemas energéticos e materiais usados na produção de bens de consumo (Dalby, 2013, p. 190), além de padróes de consumo, estilos de vida, valores, crenças e instituições correntes. Sem reflexão, a inércia será provavelmen- 
te mantida, e as consequências, conforme as evidências apresentadas pela ciência, serão bastante duras para as próximas geraçóes.

Em terceiro lugar, é essencial entender que o Antropoceno é resultado de escolhas que foram feitas pela humanidade. Escolhas são sempre políticas, e dão origem a grupos de interesse e de privilégios. Mudar as escolhas significa, sim, mudar o status quo socioeconômico e político e posicionar de forma diversa diferentes grupos. Uma parte importante dos grupos privilegiados pelo atual sistema resistirão a mudanças; se eles detêm grande poder e há mecanismos inerciais para impedir o aumento de poder de outros grupos, as barreiras para mudanças serão maiores. Não se pode ignorar essa realidade: compreender e modificar a política de poder é a diferença entre a adoção de medidas que efetivamente mitiguem a ultrapassagem das fronteiras planetárias e medidas que tratam o problema como marginal ou acessório (Dalby, 2013, p. 190; Underdal, 2010, p. 387).

\section{Interesse nacional no Antropoceno}

As bases vestfalianas da configuração do Estado como uma entidade unitária formada por território, população e governo soberano precisa ser - e tem sido - revista. Em um mundo complexo como o da sociedade da informação/conhecimento, pensar o Estado como ator unitário é irreal. A globalização tem forças centrípetas e centrífugas; promove, ao mesmo tempo, o aumento da interdependência econômica e dos intercâmbios de informação e conhecimento entre diversas partes do mundo, e a fragmentação - por meio da identificação entre grupos que dividem interesses e crenças, ainda que tenham diferentes nacionalidades; ou da articulação de interesses entre governos subnacionais e entidades extranacionais, mesmo que isso possa entrar em contradição com os interesses gerais do Estado nação (Keohane e Nye, 2001; Nye, 2011; Held et al., 1999; Biermann, 2015). É o fenômeno definido como Rosenau (2003) por "fragmegration" (palavra construída pelo autor, combinando fragmentation - fragmentação - e integration - integração).

O Estado, no século XXI, é plural: conjunto de governo, empresas, comunidade científica e so- ciedade civil (Viola, Franchini e Ribeiro, 2013), unidos ou não por um território, com interesses comuns, mas também interesses conflitantes, ou seja, comunidades plurais, heterogêneas, por vezes desagregadas nas tomadas de decisão (Scholte, 2008, p. 306; Koenig-Archibugi, 2010, p. 21). Neste sentido, como integrar em uma única definição de interesse nacional grupos heterogêneos, que podem ser muito diferentes entre si? Quando se trata dos interesses envolvidos em questôes de bens comuns globais, como a mitigação da mudança do clima, a dificuldade torna-se evidente, vez que grupos com a mesma nacionalidade têm vulnerabilidade diversa à mudança do clima, interesses diversos em relação à mudança da matriz energética e à adoção de novos padróes de consumo. $\mathrm{O}$ interesse nacional será, portanto, um amálgama dos interesses de diferentes grupos, e delineado fundamentalmente pelos dos que detêm as maiores fatias de poder político portanto, variável no tempo e no espaço.

$\mathrm{Na}$ mitigação da ultrapassagem das fronteiras planetárias, é importante observar as peculiaridades que envolvem os incentivos e a distribuição de poder político, que tornam a definição do interesse nacional nessas questóes um problema triplamente desafiador.

Em primeiro lugar, pesquisas comprovam que seres humanos valorizam mais benefícios presentes do que futuros e dedicam mais atenção ao tratamento de questôes imediatas em relação a questôes futuras (Death, 2013; Diamond, 2011; Dahl, 1972). Trocar um uso presente - por exemplo, usufruir dos sistemas energéticos e dos padróes de consumo - por um benefício futuro - a mitigação da mudança do clima -, que será, inclusive, em proveito de outras geraçóes, é encarado como um sacrifício gigantesco e resistido por grandes parcelas da população, que precisam receber incentivos para adotar novas práticas. Além disso, é preciso lidar com a realidade de que a mitigação da mudança do clima exige disciplina, persistência e adaptação ao longo do tempo: será preciso resistir, inúmeras vezes, a benefícios individuais de curto prazo para atingir os benefícios coletivos de longo prazo. Por fim, não se pode desconsiderar o fato de que a ausência dos beneficiados pelas políticas de mitigação da tomada de decisão - vez que são futuras gerações, ou, muitas vezes, futuras gerações 
descendentes das que vivem em outros países - é um terceiro e importante complicador (Underdal, 2010, pp. 387-388).

Importante salientar que o Estado não perde sua importância na política internacional deste início de século. $\mathrm{O}$ resultado da ausência de concertação internacional para obter bens comuns globais, como a mitigação da mudança do clima, será um emaranhado de açóes isoladas de natureza diversa, com objetivos que podem ser até conflitantes, e cujos resultados ficarão aquém dos necessários para mitigar verdadeiramente o problema (Hardin, 1968; Ostrom, 1990; Karlsson, 2013, p. 5). Isso não significa, no entanto, que a concertação precisa seguir o modelo existente, ineficiente para lidar com o problema.

\section{Aprofundamento da governança global}

A governança global deve ser considerada no marco da transição de uma ordem internacional para uma ordem global (Kacowicz, 2012 pp. 686688). Ela pode ser definida como a soma dos modos como indivíduos e instituiçóes, públicas e privadas, direcionam seus problemas comuns; é um processo contínuo por meio do qual interesses diversos e/ou conflitantes podem ser acomodados e a cooperação pode ser estabelecida (Naçóes Unidas, 1995).

Se a fragmegration é reconhecida e o Estado não é mais percebido como ente unitário, então a definição de soberania em bases vestfalianas deve ser modificada. A soberania passa a limitar parcialmente a maximização do interesse nacional convencional em função de alinhá-lo com o interesse geral da humanidade. Ou seja: os Estados, em sua atuação no sistema internacional, passam a reconhecer os interesses dos diferentes grupos que os compóem, além de identificar interesses comuns a toda a humanidade, e contrabalançá-los com interesse nacional strictu senso. Essa é uma postura racional, não utópica: trata-se de adaptação a uma realidade de maior incerteza e complexidade, e não de redistribuição do poder global ou à questão de equidade e justiça planetárias. ${ }^{8}$ É fruto de um cálculo de benefício de longo prazo em favor de si mesmo ainda que o benefício, por estar relacionado com bens comuns globais, se estenda também a outros atores. Encontra fundamento na matriz racionalis- ta (particularmente a liberal-institucionalista) das relações internacionais, mas um racionalismo atualizado para o século XXI: uma vez que as noçôes de ameaça, de segurança e de interesse nacional são diversas no Antropoceno, assim, o posicionamento para lidar com elas precisa ser também atualizado.

O aprofundamento da governança global nesses moldes e sua aplicação à questão da mudança do clima poderia obter resultados mais efetivos de redução de emissóes de GEE.

Dos muitos países do mundo, os que contribuem de maneira significativa para a mudança climática são poucos. São eles as potências climáticas: países que contam com uma combinação de poder militar, poder econômico e poder climático - baseado na proporção de suas emissóes no total global das emissóes de GEE, além de capital tecnológico e humano para promover a descarbonização -, que os tornam capazes de influenciar os rumos do sistema internacional em relação à questão do clima (Viola, Franchini e Ribeiro, 2013); ver Tabelas 1 e 2 . Há duas categorias de potências, conforme sua capacidade para influenciar a questão climática: as grandes potências - União Europeia, Estados Unidos, China e Índia - e as potências médias - Japão, Coreia do Sul, Brasil, Rússia, Indonésia, México, Canadá, Austrália, Turquia, Arábia Saudita, Irâ, Nigéria e África do Sul.

De acordo com a preponderância das forças sociopolíticas que influenciam o mindset e a posição das potências no ciclo global do carbono, seus posicionamentos em relação ao problema climático podem ser: (i) a favor de mudanças que verdadeiramente contribuam para mitigar o problema, reformando o regime corrente, ou (ii) contra tais mudanças, mantendo o regime atual. ${ }^{9}$ Adotando essa classificação, as potências podem ser divididas em cinco tipos: reformistas, reformistas moderadas, conservadoras moderadas, conservadoras e extremamente conservadoras.

Aplicando a classificação aos posicionamentos das potências climáticas na evolução do regime internacional sobre o clima, observa-se a predominância das potências conservadoras. A única potência reformista é a União Europeia: desde o início do regime do clima, ela tem defendido o desenvolvimento de baixo carbono e o tem promovido dentro de suas fronteiras - ainda que com imensas 
divergências e diferenças entre seus membros, além de importantes variações de ação e resultado em períodos. A União Europeia é seguida por Japão, que pode ser considerado moderadamente reformista, se focada sua trajetória no regime do clima, mas têm retrocedido na direção do conservadorismo (Viola, Franchini e Ribeiro, 2013). Sua INDC (Contribuição Nacionalmente Determinada), em particular, ficou muito aquém de suas responsabilidades: o Japáo estabeleceu o ano de 2013 como referência para sua redução de emissóes, após compromissos prévios utilizarem o ano de 1990.

São potências moderadamente conservadoras os Estados Unidos, a China, o Brasil, a Coreia do Sul, o México, a África do Sul e a Indonésia. Entre esses, extremamente relevante é a trajetória de Estados Unidos e China, que juntos respondem por mais de $40 \%$ do total global de emissões. ${ }^{10}$ Os dois países mantiveram-se conservadores ao longo da trajetória do regime climático, mas têm migrado para um conservadorismo moderado, impulsionado, inclusive, por iniciativa conjunta: assinaram, em 2014, um acordo bilateral para redução de emissões. A importância da iniciativa bilateral não deve ser minorada, em razão da interdependência entre as economias estadunidense e chinesa: são grandes competidores nos mercados internacionais, mas têm grandes parcerias produtivas; por isso, avanços bilaterais na redução de emissões podem significar maior possibilidade de cooperação de ambos no regime internacional. A Coreia do Sul era conservadora até 2005 , avançou para reformista moderada na segunda metade da década e retrocedeu para conservadora moderada a partir de 2013. A trajetória brasileira é complexa: foi conservadora até 2009, quando teve um avanço para o conservadorismo moderado; a partir de 2011, retrocedeu para o conservadorismo, pois voltou a defender posições, como o argumento das responsabilidades históricas, que havia abandonado em 2009 (Viola e Basso, 2015); em 2015, poderia ser considerado novamente conservador moderado, vez que sua INDC estabelece, pela primeira vez, um ano base para cálculo da redução de emissóes, ainda que as metas apresentadas não sejam ambiciosas.

As potências conservadoras são Índia, Canadá, Austrália e Nigéria, e as extremamente conservadoras são Rússia, Turquia, Arábia Saudita e Irã. Apesar de sua vulnerabilidade extrema à mudança do clima, a Índia é uma das mais ferrenhas defensoras do argumento da responsabilidade histórica, e o clima tem perdido prioridade na sua agenda doméstica. O Canadá era reformista até meados da década de 2000, mas retrocedeu com os governos conservadores entre 2006 e 2015. Com a derrota dos conservadores nas eleiçôes de outubro de 2015, o Canadá tende a passar gradualmente ao campo reformista moderado. A Austrália passou de conservadora para conservadora moderada em 2007 e voltou para o conservadorismo em 2013. A Rússia é uma das potências menos engajadas nas negociaçóes: tinha um nível alto de emissóes em 1990 quando ainda era parte da União das Repúblicas Socialistas Soviéticas e se beneficia, na contabilidade de emissóes, da redução que ocorreu em razão da desintegração e da redução do desenvolvimento econômico desde então. Não apresenta compromissos ambiciosos e condiciona seus pleitos à concessão de ajuda internacional, algo inacreditável para um país de renda per capita média/alta e responsável por gigantescas emissōes históricas entre 1910 e 1990.

$\mathrm{O}$ aprofundamento da governança global entre as potências climáticas pode encaminhar resultados mais efetivos do que os obtidos pelo regime do clima. Não se trata de descredenciar os demais atores de participar da solução do problema, mas de verificar que, feliz ou infelizmente, por conta da distribuição desigual de poder climático, a solução do problema está nas mãos de poucos atores. $\mathrm{O}$ regime internacional sobre mudanças climáticas assegura a participação de muitos atores com base em sua igualdade normativa, mas seu padrão de negociaçoóes segue o mínimo denominador comum: todos precisam concordar com as medidas adotadas e, por isso, os resultados acabam diluídos. Se as potências climáticas avançarem na direção do reformismo, por intermédio da adoção concertada de práticas em favor da descarbonização, os resultados para a mitigação da mudança do clima podem ser muito mais relevantes. Esse avanço poderia ser dado tanto em bases multilaterais - uma concertação climática de mais densidade, que se assemelhe ao Tratado de Não Proliferação Nuclear ou aos tratados de regulação do crescimento de arsenais nucleares entre os Estados Unidos e a União Soviética - ou em base plurilate- 
Tabela 1

As potências climáticas (2012)

\begin{tabular}{cccccc}
\hline Países & $\begin{array}{c}\text { Total de emissóes } \\
(\text { Mt CO2 e)* }\end{array}$ & $\begin{array}{c}\text { Parcela nas } \\
\text { emissóes globais } \\
(\%)\end{array}$ & $\begin{array}{c}\text { Emissóes per } \\
\text { capita } \\
\text { (t CO2 e)** }\end{array}$ & $\begin{array}{c}\text { PIB per capita } \\
\text { (USD intl } \\
2011)^{* * *}\end{array}$ & $\begin{array}{c}\text { Trajetória recente } \\
\text { de emissóes }\end{array}$ \\
\hline China & $10.684,29$ & 22,45 & 7,91 & $10.756,46$ & aumento \\
\hline Estados Unidos & $5.822,87$ & 12,23 & 18,55 & $50.585,66$ & constante \\
\hline UE-28 & $4.122,64$ & 8,66 & 8,22 & $34.487,61$ & reduçáo \\
\hline Índia & $2.887,08$ & 6,07 & 2,33 & $4.966,81$ & aumento \\
\hline Rússia & $2.254,47$ & 4,74 & 15,75 & $23.309,80$ & constante \\
\hline Indonésia & $1.981,00$ & 4,16 & 8,02 & $8.855,01$ & aumento \\
\hline Brasil & $1.823,15$ & 3,83 & 9,18 & $14.323,14$ & aumento \\
\hline Japão & $1.207,30$ & 2,54 & 9,46 & $34.987,61$ & constante \\
\hline Canadá & 856,28 & 1,80 & 24,64 & $41.543,70$ & aumento \\
\hline México & 748,91 & 1,57 & 6,20 & $16.316,34$ & aumento \\
\hline Irá & 711,88 & 1,50 & 9,31 & $16.233,52$ & aumento \\
\hline Austrália & 685,05 & 1,44 & 30,14 & $42.521,61$ & aumento \\
\hline Coreia do Sul & 661,39 & 1,39 & 13,23 & $31.901,07$ & aumento \\
\hline Arábia Saudita & 526,97 & 1,11 & 18,63 & $51.122,15$ & aumento \\
\hline Nigéria & 474,86 & 1,00 & 2,81 & $5.290,86$ & aumento \\
\hline África do Sul & 463,75 & 0,97 & 8,86 & $12.374,53$ & aumento \\
\hline Turquia & 390,86 & 0,82 & 5,28 & $18.057,16$ & aumento \\
\hline
\end{tabular}

${ }^{*} \mathrm{Mt} \mathrm{CO} 2 \mathrm{e}=$ milhóes de toneladas de $\mathrm{CO} 2$ equivalente

** t CO $2 \mathrm{e}=$ toneladas de $\mathrm{CO} 2$ equivalente

*** USD intl 2011 = dólar internacional em 2011

Nota: O total de emissóes, a parcela nas emissóes globais e as emissóes per capita incluem emissóes por mudança de uso da terra.

Fonte: Elaboração própria, com dados do World Resources Institute, Climate Data Explorer. Disponível em: <http://cait.

wri.org/historical/>. Acesso em: 3 abr. 2016.

ral. ${ }^{11}$ Central é o avanço das práticas das potências na direção do reformismo, ou seja, em favor de mais ampla descarbonização de suas economias.

\section{Conclusão}

O fim do século XX e início do século XXI são palco de uma transformação sem precedente na história: inaugurou-se o Antropoceno, nova época geológica e humana em que o meio ambiente deixa de ser estável, mero pano de fundo dos dramas humanos, para tornar-se instável, questão central nas preocupaçóes humanas, especialmente em relação à sobrevivência no longo prazo. Mitigar a instabilidade ambiental é bem comum global; requer concertação internacional com cessão parcial da soberania dos Estados em prol de uma governança global mais efetiva.

Com o advento da revolução digital e a configuração da sociedade da informação/conhecimento, conceitos tradicionais das relaçóes internacionais foram atualizados. O Estado deixou de ser a ficção de um ator unitário para ser visto como pluralidade, conjunto de governo, empresas, comu- 


\section{Tabela 2}

\section{Os 10 maiores produtores de combustíveis fósseis (2014)}

\begin{tabular}{cccccc}
\hline $\begin{array}{c}\text { Carvão total } \\
(\mathrm{Mt})\end{array}$ & $\begin{array}{c}\text { Mundo } \\
(\%)\end{array}$ & $\begin{array}{c}\text { Petróleo total } \\
(\mathrm{Mt})\end{array}$ & $\begin{array}{c}\text { Mundo } \\
(\%)\end{array}$ & $\begin{array}{c}\text { Gás total } \\
(\mathrm{bcm})\end{array}$ & $\begin{array}{c}\text { Mundo } \\
(\%)\end{array}$ \\
\hline China (3.650) & 46,1 & Arábia Saudita (542) & 12,9 & EUA (730) & 20,7 \\
\hline Estados Unidos (916) & 11,6 & Rússia (529) & 12,6 & Rússia (664) & 18,3 \\
\hline Índia (668) & 8,4 & EUA (509) & 12,1 & Irã (169) & 4,8 \\
\hline Austrália (491) & 6,2 & China (212) & 5,0 & Canadá (162) & 4,6 \\
\hline Indonésia (471) & 5,9 & Canadá (208) & 5,0 & Qatar (160) & 4,5 \\
\hline Rússia (334) & 4,2 & Irá (166) & 4,0 & China (130) & 3,7 \\
\hline África do Sul (253) & 3,2 & Iraque (160) & 3,8 & Noruega (113) & 3,2 \\
\hline Alemanha (187) & 2,4 & Kuwait (158) & 3,8 & Turcomenistáo (87) & 2,5 \\
\hline Polônia (137) & 1,7 & Emirados Árabes (157) & 3,7 & Arábia Saudita (84) & 2,4 \\
\hline Cazaquistáo (115) & 1,5 & Venezuela (151) & 3,6 & Argélia (80) & 2,3 \\
\hline Mundo (7.925) & 100,0 & Mundo (4.200) & 100,0 & Mundo (3524) & 100,0 \\
\hline
\end{tabular}

${ }^{*} \mathrm{Mt}=$ Milhões de Toneladas.

**bcm: Bilhóes de Metros Cúbicos

Fonte: Elaboração própria, com dados da International Energy Agency (IEA), Key World Energy Statistics 2015. Disponível em <http://www.iea.org/publications/>. Acesso em: 20 jan. 2016.

nidade científica e sociedade civil, que têm interesses comuns, mas também interesses conflitantes. Interesse nacional deixou de ser a resultante natural de interesses do ator unitário para ser compreendido como resultado da luta política entre diversos grupos, que detêm diferentes fatias de poder, e, por isso, variável no tempo e no espaço. No Antropoceno, também o conceito de ameaça à segurança é modificado: não apenas as guerras simétricas entre potências - atualmente bastante improváveis, vez que o prejuízo mútuo seria enorme - colocariam o sistema internacional em risco, mas também os efeitos da instabilidade ambiental. A diferença é que a instabilidade ambiental já é realidade, e poderá agravar-se ainda mais caso não sejam tomadas efetivas medidas para sua mitigação.

Mitigar a ultrapassagem de um dos limites planetários, a mudança do clima, preveniria que às atuais alterações incrementais do sistema climático eventos climáticos extremos cada vez mais frequentes - sejam somados: aumento do potencial de destruição de produção agrícola; aprofundamento da escassez de água doce; extremos climáticos mais intensos; aumento da turbulência do mar e ondas anormais que invadem temporariamente as regióes costeiras; aumento significativo do nível do mar; aceleração do derretimento do gelo na Groenlândia. Prevenindo-se a mudança climática perigosa, evita-se a mudança climática catastrófica.

Para que a mitigação seja factível, é crucial que as potências climáticas - países com capacidade real de influenciar a mudança do clima, dado o montante de suas emissóes de carbono e seu potencial humano e tecnológico para promover a descarbonização - adotem posturas reformistas em relação ao atual regime do clima. Ou seja: que se comprometam efetivamente com medidas que façam avançar a descarbonização de suas economias.

Atualmente, há maiorias reformistas na União Europeia e importantes minorias em quase todos os países-chave para a governança global do clima - Japão, Estados Unidos, China, Índia, Coreia do Sul, Indonésia, Brasil, México, África do Sul, Austrália e Canadá. Porém, forças conservadoras ain- 
da são majoritárias. Como a principal ferramenta desenvolvida para lidar com o problema climático, o regime internacional sobre mudança do clima, adota o princípio da igualdade normativa entre os países, as medidas adotadas requerem consenso universal. Dada a hegemonia conservadora, esse mínimo denominador comum é insuficiente para mitigar a mudança do clima. Um bom exemplo é o acordo obtido na Conferência de Paris, em dezembro de 2015. Em nível diplomático, o acordo foi um sucesso, pois une em consenso interesses nacionais e setoriais diferentes e muitas vezes antagônicos. Também foi bem sucedido em estabelecer o nível máximo de aumento da temperatura global em 1,5 grau centígrado, e não 2 graus centígrados. No entanto, o conteúdo do compromisso afirmado é insuficiente para promover profunda descarbonização global: países apresentaram metas meramente voluntárias, e não obrigatórias, de redução de emissóes, que, se totalmente implementadas, conduziriam o aumento da temperatura global a 2,7 graus centígrados no longo prazo; o sistema de monitoramento da implementação das metas é fraco, portanto não há garantia de implementação; a revisão das metas, a ser feita a cada cinco anos, não obriga os países a aprofundarem seus compromissos; o conceito de descarbonização foi eliminado do acordo, e também inexiste referência ao fim dos subsídios aos combustíveis fósseis, condição necessária para que a descarbonização global seja efetiva; o acordo fala em transferência de recursos de países desenvolvidos aos pobres - economias emergentes, com exceção da China, negaram-se -, mas o montante é pequeno e o acordo náo esclarece que parcela teria fontes públicas (os únicas que poderiam ser cobradas). Maior densidade na concertação entre esses países seria obtida se negociado um tratado nos moldes mais rigorosos do multilateral do Tratado de Não Proliferação Nuclear (TNP) ou dos quatro tratados bilaterais americanos/soviéticos/russos para a regulação do crescimento de arsenais nucleares (SALT 1, de 1969 e SALT 2, de 1979) e para a redução dos arsenais nucleares (START 1, de 1991 e START 2, de 1993) ou se os países engajarem-se em negociaçóes plurilaterais que toquem os temas acima. Certamente são alternativas mais eficazes para mitigar a mudança climática.
Vive-se, atualmente, uma janela de oportunidade: decisóes que forem tomadas nas próximas duas décadas darão origem a consequências que serão experimentadas na segunda metade do século XXI e nos próximos séculos. Assegurar a estabilidade do planeta é pensar além da segurança energética ou das consequências de espaços não governados: é refletir honesta e abertamente sobre sistemas energéticos e materiais usados na produção de bens de consumo, além de padrốes de consumo, estilos de vida, valores, crenças e instituiçóes correntes. $\mathrm{O}$ fator decisivo para essa transformação está no crescimento de forças reformistas nas potências climáticas e uma concertação mais estreita entre elas, em que a soberania seja cedida parcialmente em prol de tratados plurilaterais fortes, nos quais o compromisso com a descarbonização seja obrigatoriamente implementado. Essa mudança não é fácil: na verdade, é muito mais desafiadora do que a concertação dos mais de duzentos atores partes do regime internacional do clima. Porém, se ocorrer, será evidência de que está sendo atualizada a matriz cognitiva de interpretação da realidade em que se vive, provando que a espécie humana é capaz de adaptar estruturas institucionais e políticas para assegurar sua sobrevivência no mundo do século XXI.

\section{Notas}

1 Antes dos combustíveis fósseis, as fontes de energia eram a luz e o calor sol, o movimento do vento e das águas, e a biomassa, especialmente a lenha, que dependiam de serem encontradas na natureza e não podiam ser deslocadas por longas distâncias.

2 Se levadas em consideração as emissóes de 2008, início do prazo do compromisso de redução de emissóes, a parcela chegava a $27,41 \%$ das emissóes globais. Caso os Estados Unidos tivessem ratificado o Protocolo, a porcentagem teria subido para $51,34 \%$, em números de 2005, e 46,46\% em números de 2008. Todos cálculos próprios com base em IEA (2007; 2010). Não foram encontrados dados para Liechtenstein e Mônaco.

3 Vide relação da US Climate Network, disponível em: <http://www.usclimatenetwork.org/policy/copenhagen-accord-commitments>; acesso em: 15 fev. 2016.

4 Até 11 de fevereiro de 2016, 60 países haviam ratificado a Emenda de Doha, número insuficiente para 
sua entrada em vigor, Informaçóes disponíveis em: $<$ http://unfccc.int/kyoto_protocol/doha_amendment/items/7362.php>; acesso em: 11 fev. 2016.

5 Cálculos próprios com base nas publicações citadas.

6 A Aliança dos Pequenos Estados Ilhas, por exemplo, é muito atuante no regime do clima e pressiona por compromissos mais ambiciosos, visto que representa países que tendem a submergir em razão da elevação do nível do mar. Tem pouca influência no regime, porém.

7 Cálculo feito para as INDCs apresentadas até 8 de dezembro de 2015.

8 Para as correntes que defendem a redistribuição de poder, o aprofundamento da governança global e a mitigação do conceito de soberania vestfaliana sáo oportunidades de mudar a balança de poder no mundo, alcançando uma sociedade internacional mais igualitária e mais justa, conforme inspiração da doutrina kantiana. Essa postura, ainda que incorporada por parcelas da população mundial, é utópica em escala global. Para que essa realidade se altere, é necessária uma mudança significativa da matriz cognitiva humana para aceitar reduzir benefícios próprios em favor de outros. Oxalá esta mudança se concretize nas próximas décadas.

9 Importante ressaltar que se trata de uma classificação geral; sempre haverá, dentro das sociedades que formam as potências climáticas, nuances que distinguem os diversos posicionamentos em pontos específicos.

10 A saber: 41,84\% em 2012 e 43,79\% em 2013, de acordo com dados da IEA (2014; 2015), que excluem mudanças de uso da terra.

11 A literatura tem explorado a opçáo de clubes de descarbonização, fóruns que reúnam os principais emissores de gases de efeito estufa, como estratégia para aumentar a ambição dos compromissos internacionais no tema. O G-20, por exemplo, já foi estudado (Van den Graff e Westphal, 2011). A eficácia de clubes em prover a concertação climática é defendida por permitir a barganha entre os membros em torno de bens providos pelo grupo, que poderiam estar vinculados a compromissos de redução de emissóes, incentivando-os a adotar medidas de mitigaçáo da mudança do clima (Victor, 2015; Hovi et al., 2015).

\section{BIBLIOGRAFIA}

BIERMANN, Frank et al. (2012), "Planetary boundaries and earth system governance: exploring the links". Ecological Economics, 81: 4-9.
. (2015), Earth system governance: world politics in the Anthropocene. Cambridge, The MIT Press.

CLIMATE ACTION TRACKER. (2015), "Climate Action Tracker Update: $2.7^{\circ} \mathrm{C}$ is not enough - we can get lower". Disponível em: <http://climateactiontracker.org/assets/publications/briefing_papers/CAT_Temp_Update_COP21.pdf >. Acesso em: 12 fev. 2016.

CRUTZEN, Paul \& STOERMER, Eugene. (2000), "The Anthropocene". Global Change Newsletter, 41: 17-18.

DAHL, Robert. (1972), Polyarchy: participation and opposition. New Haven, Yale University Press.

DALBY, Simon. (2013), "Biopolitics and climate security in the Anthropocene". Geoforum, 49: 184-192.

(2014), "Rethinking geopolitics: climate security in the Anthropocene. Global Policy Journal, 5 (1): 1-9.

DEATH, Carl (org.). (2013), Critical Environmental Politics. Londres/Nova York, Routledge.

DIAMOND, Jarrel. (2011), Collapse: how societies choose to fail or succeed. Revised edition. Nova York, Penguin Books.

DIESENDORF, Mark. (2011), "Redesigning energy systems", in John S. Dryzek; Richard B. Norgaard e David Schlosberg (eds.), The Oxford handbook of climate change and society, Oxford, Oxford University Press.

DUBASH, Navroz. (2010), "Copenhagen: climate of distrust". Economic and Political Weekly, 44 (52): 8-11.

GUPTA, Joyeeta. (2010), "A history of international climate change policy". WIREs Climate Change, 1: 636-653.

HALLDING, Karl et al. (2011), Together alone: basic countries and the climate change conundrum. Copenhagen, Nordic Council of Ministers.

HARDIN, Garrett. (1968), "The tragedy of commons”. Science, 162 (3859): 1243-1248.

HELD, David et al. (1999), Global Transformations. Redwood City, Stanford University Press.

HOGE, James F. (2010), “The world ahead”. Foreign Affairs, 89 (6): i-ii. 
HOVI, Jon et al. (2015), "The club approach: a gateway to effective climate cooperation?". Paper presented at a Second Environment and Sustainability Forum, University of Bath, 9-11 Apr. 2015. Disponível em: <http://www.bath. ac.uk/ipr/pdf/events/climate-change/Hovi. pdf>. Acesso em: 12 fev. 2016.

IEA - International Energy Agency. (2007), "Key World Energy Statistics 2007”. Disponível em: <http://www.iea.org/publications/>. Acesso em: 15 dez. 2013.

(2010), "Key World Energy Statistics 2010”. Disponível em: <http://www.iea.org/ publications/>. Acesso em $15 \mathrm{dez} .2013$.

. (2013), "Key World Energy Statistics 2013”. Disponível em: <http://www.iea.org/ publications/>. Acesso em: 20 jul. 2014.

. (2014), "Key World Energy Statistics 2014”. Disponível em: <http://www.iea.org/ publications/>. Acesso em: 10 nov. 2015.

. (2015), "Key World Energy Statistics 2010”. Disponível em: <http://www.iea.org/ publications/>. Acesso em: 20 jan. 2016.

JAMIESON, Dale. (2011), "The nature of the problem”, in John S. Dryzek; Richard B. Norgaard e David Schlosberg (eds.), The Oxford handbook of climate change and society, Oxford, Oxford University Press.

KACOWICZ, Arie M. (2012), "Global governance, international order and world order", in David Levi-Faur (ed.), The Oxford handbook of governance, Oxford, Oxford University Press.

KARLSSON, Rasmus. (2013), "Ambivalence, irony, and democracy in the Anthropocene". Futures, 46: 1-9.

KEOHANE, Robert \& NYE, Joseph. (2001), Power and interdependence. 2 ed. Cambridge, Cambridge University Press,

KOENIG-ARCHIBUGI, Mathias. (2010), "Understanding the global dimensions of policy". Global Policy Journal, 1 (1): 16-28.

NAIM, Moises. (2013), The end of power. Philadelphia, Perseus Group.

NAÇÓES UNIDAS. (1995), "Our global neighbourhood. Report of the Commission on Global Governance”. Disponível em: <http:// www.gdrc.org/u-gov/global-neighbourhood/ chap1.htm>. Acesso em: 28 jun. 2014.

NYE, Joseph. (2011), The future of power. Cambridge, Cambridge University Press.

OSTROM, Elinor. (1990), Governing the commons: the evolution of institutions for collective action. Cambridge, Cambridge University Press.

PARSONS, Edward \& ERNST, Lia. (2014), "International governance of climate engineering". Theoretical Inquiries in Law, 14: $307-$ 338.

ROCKSTROM, Johan et al. (2009), "A safe operating space for humanity”. Nature, 461: 472475.

ROSENAU, James N. (2003), "Globalization and governance: bleak prospects for sustainability". International Politics and Society (IPG), 3. Disponível em: <http://www.fes.de/ipg/ IPG3_2003/ARTROSENAU.HTM>. Acesso em: 10 nov. 2014.

SCHOLTE, Jan Aart. (2008), "Reconstructing contemporary democracy". Indiana Journal of Global Legal Studies, 15 (1): 305-350.

STEFFEN, Will. (2011), "A truly complex and diabolical policy problem”, in John S. Dryzek; Richard B. Norgaard e David Schlosberg (eds.), The Oxford handbook of climate change and society, Oxford, Oxford University Press.

STEFFEN, Will et al. (2011), "The Anthropocene: conceptual and historical perspectives". Philosophical Transactions of The Royal Society, 369: 842-867.

. (2015), "Planetary boundaries: guiding human development on a changing planet". Science, 347 (6223): 1-16.

THE ROYAL SOCIETY. (2012), "People and the planet report". Londred, The Royal Society.

UNDERDAL, Arild. (2010), "Complexity and challenges of long-term environmental governance". Global Environmental Change, 20: 386-393.

VAN DEN GRAAF, Thijs \& Westphal, Kirsten. (2011), "G-8 and G-20 as steering committees for energy”. Global Policy Journal, 2 (special issue): $19-30$.

VEIGA, José Eli da. (2013), A desgovernança mundial da sustentabilidade. São Paulo, Editora 34. 
VICTOR, David. (2015), The case for climate clubs. Report of the E15 Initiative - strengthening the global trade and investment system for sustainable development. Genebra, ICTSD.

VIOLA, Eduardo. (2002), "O regime internacional de mudança climática e o Brasil”. Revista Brasileira de Ciências Sociais, 17 (50): 25-46.

VIOLA, Eduardo \& BASSO, Larissa. (2015), "Brazilian energy-climate policy and politics towards low carbon development". Global Society, 29 (3): 427-446.

VIOLA, Eduardo; FRANCHINI, Matias \& RIBEIRO, Thais Lemos. (2012), "Climate governance in an international system under conservative hegemony: the role of major powers". Revista Brasileira de Politica Internacional, 55 (special edition): 9-29.

. (2013), Sistema internacional de hegemonia conservadora: governança global e democracia na era da crise climática. São Paulo, Annablume. 


\section{O SISTEMA INTERNACIONAL NO ANTROPOCENO}

\section{Eduardo Viola e Larissa Basso}

Palavras-chave: Antropoceno; Mudança climática; Descarbonizaçáo; Governança global; Soberania.

No final do século XX e início do século XXI, uma nova época geológica teve início, o Antropoceno. Ele é caracterizado pela perda da estabilidade ambiental em razão da interferência humana, do impacto cumulativo do desenvolvimento econômico sobre o meio ambiente. A mudança é sem precedentes na experiência humana; mitigá-la significa assegurar uma existência mais segura para a humanidade. Essa mitigação, porém, requer concertação internacional muito mais densa do que a que tem sido observada no regime internacional sobre mudança do clima. A construção de alianças de descarbonização entre países-chave para a resolução do problema é crucial. Ela será possível mediante a revisão dos conceitos de ameaça, segurança e interesse nacional, e uma nova interpretação da soberania, em que interesses comuns da humanidade sejam incorporados ao fundamento vestfaliano. É uma mudança complexa, mas que atualizará fundamentos importantes para uma geopolítica capaz de lidar com questóes do século XXI.

\section{THE INTERNATIONAL SYSTEM IN THE ANTHROPOCENE}

\author{
Eduardo Viola and Larissa Basso
}

Keywords: Anthropocene; Climate change; Decarbonization; Global governance; Sovereignty

In the end of the $20^{\text {th }}$ and beginning of the $21^{\text {st }}$ century, a new geological epoch emerged: the Anthropocene. In this new epoch, the environmental stability is lost due to the human interference and the impact of economic development upon the environment. Such is an unprecedented change in human experience and needs to be mitigated in order to allow a safer human existence. Mitigation requires a lot more intense international cooperation than the one observed in the international regime on climate change. Alliances between key countries for the resolution of the decarbonization problem are crucial. They might be obtained if new interpretations of threat, security, and national interest are accepted along with a revision of the conception of sovereignty in which common global interests of the humanity are incorporated. What it is about is a complex change, but a change that will update important foundations of a geopolitics able to deal with the questions put forward by the $21^{\text {st }}$ century.

\section{LE SYSTÈME INTERNATIONAL DANS L'ANTHROPOCẼNE}

\author{
Eduardo Viola et Larissa Basso
}

Mots-clés: Anthropocène; Changement climatique; Décarbonisation; Gouvernance globale; Souveraineté.

À la fin du XX ${ }^{\text {ème }}$ et au début du XXI ${ }^{\text {ème }}$ siècle, une nouvelle ère géologique a vu le jour: l'Anthropocène. Elle se caractérise par la perte de la stabilité environnementale en conséquence de l'interférence humaine, de l'impact cumulatif du développement économique sur l'environnement. Ce changement n'a pas de précèdent dans l'expérience humaine ; l'atténuer signifie assurer une existence plus rassurante pour l'humanité. Cette atténuation requiert, néanmoins, une concertation internationale beaucoup plus intense que celle que l'on peut observer à propos du régime international sur les changements climatiques. La construction d'alliances de décarbonisation entre des pays-clés s'avère cruciale pour la résolution du problème. Elle ne sera possible que par la révision des concepts de menace, de sécurité et d'intérêt national, et une nouvelle interprétation de la souveraineté, dans laquelle les intérêts communs de l'humanité soient incorporés au fondement westphalien. C'est un changement complexe, mais qui mettra à jour des bases importantes pour une géopolitique capable de faire face aux questions actuelles du XXI ${ }^{\text {ème }}$ siècle. 